\title{
Identification of elite performance characteristics specific to anthropometric characteristics, athletic skills and motor competencies of combat athletes
}

Authors' Contribution: A Study Design B Data Collection C Statistical Analysis D Data Interpretation E Manuscript Preparation F Literature Search G Funds Collection

\author{
Hilal Gürsoy ${ }^{A B D F}$, Umut CanliACDEF
}

School of Physical Education and Sports, Tekirdag Namık Kemal University, Tekirdağ, Turkey

\section{abstract}

Background: Knowing all the features required for elite performance in sports disciplines under the name of combat sports is among the most important parameters for discipline-specific talent identification and selection.

Material and methods:

The research group consists of male and female athletes within the age range of 12-17 who are licensed in taekwondo, karate, judo, and wrestling. A total of 70 athletes, 21 elite and 49 non-elite athletes, participated in the study voluntarily. Anthropometric, athletic and motor competency tests were applied to determine the elite performance elements of the groups.

Results: Comparing the elite and non-elite athletes, statistically significant differences were found in favor of the elite group $(p<0.05)$ in terms of height, sitting height, body weight, speed, core endurance, grip strength, upper extremity strength, anaerobic power, KTK jumping sideways and hopping. There was no statistical difference between the groups in terms of fat percentage, BMI, agility, vertical jump, flexibility, KTK moving sideways and walking backwards values $(p>0.05)$.

Conclusions:

There seem to be important distinctions between athletes who reach the national peak and those who do not, in terms of height, sitting height, body weight, speed, anaerobic power, grip strength, upper extremity and core strength, as well as motor competency related to anaerobic power.

Key words: athletic skill, anthropometric characteristic, motor competency, combat athletes.

\section{article details}

Article statistics: Word count: 4,409; Tables: 6; Figures: 0; References: 50

Received: August 2021; Accepted: November 2021; Published: December 2021

Full-text PDF: http://www.balticsportscience.com

Copyright @ Gdansk University of Physical Education and Sport, Poland

Indexation: Celdes, Clarivate Analytics Emerging Sources Citation Index (ESCI), CNKI Scholar (China National Knowledge Infrastructure), CNPIEC, DOAJ, EBSCO - Central \& Eastern European Academic Source, EBSCO - SPORTDiscus, EBSCO Discovery Service, Google Scholar, Index Copernicus, J-Gate, Naviga (Softweco, Primo Central (ExLibris), ProQuest - Family Health, ProQuest - Health \& Medical Complete, ProQuest - Illustrata: Health Sciences, ProQuest Nursing \& Allied Health Source, Summon (Serials Solutions/ProQuest, TDOne (TDNet), Ulrich's Periodicals Directory/ ulrichsweb, WorldCat (OCLC)

Funding: This research received no specific grant from any funding agency in the public, commercial, or not-for-profit sectors.

Conflict of interests: Corresponding author:

Open Access License: Authors have declared that no competing interest exists.

Umut CANLI, Namik Kemal Street, Ozgul Avenue No: 4/36 Tekirdag/TURKEY; phone: +90 54463985 52; e-mail: ucanli@nku.edu.tr

This is an open access article distributed under the terms of the Creative Commons Attribution-Non-Commercial-NoDerivatives 4.0 International (https://creativecommons.org/licenses/by-nc-nd/4.0/), which permits use, distribution, and reproduction in any medium, provided the original work is properly cited, the use is non-commercial and is otherwise in compliance with the license. 


\section{INTRODUCTION}

Judo, taekwondo, karate, wrestling and other combat sports have become popular in recent years with the increasing number of participants worldwide [1]. With this increasing popularity, coaches and federations need evidence-based talent identification and development programs. The key question in talent identification is deciding which athlete has the potential to perform best and be successful at the highest level of competition [2]. For this, it is necessary to know the various performance and anthropometric characteristics of the athletes in order to be successful in a wide variety of combat sports [3]. In particular, over the past decade, profiles of athletes active in different disciplines of combat sports such as wrestling [4], judo [3,5] and taekwondo [6] and profiles of athletes active at various levels of participation have been partially documented. In our country, it is expected that the performance elements of judo, taekwondo, karate and wrestling, which are defined as combat sports, will be determined, and that multidimensional and elite performance criteria will be revealed.

One of the sports disciplines classified under the name of combat sports is judo. In the body of literature, there are studies comparing the body composition elements and athletic characteristics of judokas defined as elite and non-elite in different age and weight categories $[7,8,9]$. Some researchers consider maximum explosive power and endurance to be the most important physical abilities for judokas [10, 11]. Another combat sport is taekwondo, an indigenous Korean martial art that emerged thousands of years ago and has become a popular sport with more than 120 million children and adults actively participating in it worldwide [1]. In this discipline, heights between $170 \mathrm{~cm} \mathrm{[12]} \mathrm{and} 183 \mathrm{~cm}$ [6] are reported for adult male elite athletes, but high standard deviations are also reported in these findings. Taekwondo athletes with good lower extremity explosiveness generate more power during kicking, which gives them an advantage during competition [13]. In addition, it is reported that the speed of practice plays a key role in achieving success in taekwondo sport [6, 14]. Karate, one of the Far East combat sports, is defined as a respect sport in which the competitions begin with greeting the opponent and end with the greeting [15]. There are studies comparing some performance elements at elite and sub-elite levels of karate players in youth leagues. There are many studies showing that elite athletes' decision-making speed is faster than sub-elite players in reactive tests [16, 17]. For example, Gabbett and Benton's [16] reactive agility test showed that the speed of decision making and movement was faster in elite players. One of the sports classified as combat sport is wrestling, which is defined as our ancestors' sport, and which has a very important place in Turkish history. It has been determined that wrestlers are among the strongest athletes when their body weight is evaluated as a criterion [18]. In many studies, it has been reported that strength performance stands out as the most important factor among the performance indicators of wrestlers, while the anaerobic energy system is predominantly used, and factors such as speed, flexibility, balance, muscular and cardiovascular endurance, and coordination also affect performance [19]. There are also studies comparing the physical and physiological parameters of elite and non-elite wrestlers [4, 20].

In summary, it is seen that evaluations are made in terms of the anthropometric and physiological elements of the athlete performance profiles of combat sports disciplines such as judo, taekwondo, karate and wrestling. However, it has been determined that the number of studies comparing elite and non-elite combat athletes in terms of motor coordination is quite low, also in Turkey. In addition, criteria that can be used in talent identification, development and selection processes have not been established by determining the performance characteristics of elite athletes. It is thought that determining the characteristic features of combat athletes related to their disciplines and knowing what the necessary qualifications for elite performance level are will contribute to both the trainers and the relevant federations and indirectly to the development of Turkish sports. At the same time, 
it is thought that the results obtained from the research will contribute to the creation of talent identification, development and selection criteria that should be designed under the name of combat sports, which is another factor that increases the importance of the research.

In this direction, this study aimed to determine how and in which parameters elite and nonelite combat athletes differ in terms of athletic skills, anthropometric characteristics and motor competencies.

\section{MATERIALS AND METHODS}

\section{PARTICIPANTS AND DESIGN}

The research group consists of male and female athletes between the ages of 12-17 who are licensed in the disciplines of taekwondo, karate, judo and wrestling in sports clubs located in Tekirdağ province and its districts. The necessary ethics committee approval (Protocol No: 2021.109.04.04) was obtained for the research from the Tekirdağ Namık Kemal University Scientific Research and Publication Ethics Committee. In order for the athletes to be included in the research, they had to meet the following conditions: no orthopedic, cardiological or neurological disease that would prevent the movements to be made during the measurements and tests, no engagement in strenuous physical activity before the measurements, and no use of painkillers or sleep-inducing drugs the day before the measurements. In addition, not participating in training for various reasons (injury, illness, etc.) for more than three (3) months excluded the athletes from the study. Furthermore, necessary permissions were obtained from the athletes' clubs. In addition, voluntary and parent consent forms containing information about the purpose, goal, method and permission of the research were sent to the families of the athletes, and the athletes who received permission were included in the study. Within the scope of the study, two groups of elite and non-elite athletes were formed. The elite group is defined as the athletes in the Turkish National Teams in their own discipline, and the non-elite group is defined as the athletes in local leagues. A total of 70 athletes, 21 elite and 49 non-elite athletes, voluntarily participated in the study. The detailed frequency distributions related to the age and gender characteristics of the study group are given in Table 1.

Table 1. Age and gender frequencies of athletes in terms of being elite and non-elite

\begin{tabular}{|c|c|c|c|c|c|}
\hline \multirow{2}{*}{ Age (year) } & \multicolumn{2}{|c|}{ Elite } & \multicolumn{2}{|c|}{ Non-elite } & \multirow{2}{*}{ Total } \\
\hline & Male & Female & Male & Female & \\
\hline 12 & - & - & 6 & 6 & 12 \\
\hline 13 & - & 1 & 2 & 6 & 9 \\
\hline 14 & 1 & 1 & 5 & 7 & 14 \\
\hline 15 & 4 & 2 & 5 & 2 & 13 \\
\hline 16 & 4 & 1 & 4 & 5 & 14 \\
\hline 17 & 2 & 5 & 1 & - & 8 \\
\hline Total & 11 & 10 & 23 & 26 & 70 \\
\hline
\end{tabular}

\section{MEASUREMENTS}

Anthropometric measurements, athletic skill tests and motor coordination tests were applied to the athletes by the researchers. All measurements and tests were carried out in the same order and by the same researchers. The athletes performed all tests barefoot with the exception of athletic skill tests, and motor coordination tests, which were all performed with running shoes. Detailed explanations about measurements and tests are given below. 


\section{ANTHROPOMETRY}

Body height and sitting height were measured using a calibrated stadiometer $(0.1 \mathrm{~cm}$, Mesilife 13539 brand portable stadiometer). In addition, body weight and body fat percentage were assessed using a digital balance scale with a foot-to-foot bioelectrical impendence system (0.1 kg, Tanita, BC 545N) according to previously described procedures [21] and manufacturer's guidelines. Body height and body weight values were used to calculate the Body Mass Index (BMI in kg/m2).

\section{ATHLETIC SKILL}

The athlete was in a standing upright position. The dynamometer (Takei brand handgrip dynamometer) was in the athlete's dominant hand. The athlete squeezed the handle of the dynamometer explosively for 5 seconds without breaking the grip. The force applied by the athlete was read from the display of the dynamometer. The test was repeated twice, 1 minute apart, and the best value was recorded on the data sheet. In this test, the hand grip strength of the athlete was determined. Speed was evaluated by two maximal sprints of 20 meters. The recovery time between each sprint was set at two minutes. The fastest time for $20 \mathrm{~m}$ sprint was used for analysis [22]. Pro-agility test was used as the agility test. The course of the test was determined by placing markers 5 yards $(4.57 \mathrm{~m})$ left and right of the starting line. Photocell door was placed on the starting line. Repetitive transition times were obtained in this way. The athlete took his/her place at the starting line before the practice started. When the athlete was ready, he/she first touched the right marker, then the left marker, and finally passed the starting line, ending the test [23]. The measurement was made twice. A rest interval of 3 minutes was given between measurements. The measurement with the lowest second of the two measurements was used in statistical analysis. The counter movement jump (CMJ) was performed to estimate explosive leg power. The athletes performed three single jumps without arm swing recorded with a Myotest device accelerometer (Myotest S.A., İsviçre), and the highest of the three jumps was used for further analysis $(0.1 \mathrm{~cm})$. Anaerobic power values were determined automatically by the myotest device as a result of entering the necessary information into it. The Sport-Specific Core Muscle Strength and Stability Plank Test, covering a period of 180 seconds, was used to observe the core strength and core stability development of the athletes. With the start of the time, the time until the athlete got tired and/or broke his/her posture was recorded in seconds [24]. The athletes' upper extremity strength was determined with the medicine ball shot test. Athletes tried to throw the medicine ball weighing $2 \mathrm{~kg}$ from the top of the head with both hands as far as possible from where they were standing. The longest throw distance at the end of two trials was recorded as the test score in centimeters [25]. Flexibility was assessed by the modified sit-and-reach test of with an accuracy of $0.5 \mathrm{~cm}$ [26].

\section{MOTOR COORDINATION}

Participants' motor coordination levels were assessed with the Körperkoordinationstest für kinder (KTK) test [27]. KTK consists of four subtests: balance, jumping, jumping and carrying. The KTK balance test is in the form of walking backwards on slats of $3 \mathrm{~m}$ length and different widths $(3 \mathrm{~cm}, 4.5 \mathrm{~cm}, 6 \mathrm{~cm}) 3$ times, taking a maximum of 8 steps in each. KTK jumping test involves jumping over foam obstacles with both feet, respectively. The KTK jump test consists of two consecutive sideways (right-left) double-leg jumps over a 2 $\mathrm{cm}$ high wooden stick for 15 seconds. The KTK carrying test is the displacement of the body from one to the other of 2 square boards with a side length of $25 \mathrm{~cm}$ within 20 seconds.

\section{PROCEDURES}

The test procedure was explained in detail to the athletes and trainers by the researchers, both theoretically and practically. On the first day of the tests and measurements, the athletes were first asked to fill in the form containing their descriptive characteristics. Then, anthropometric measurements, respectively, height, sitting height, body weight, and body 
fat percentage values were measured. Later, the KTK test, which is a motor coordination test, was applied respectively as the side jump, jump, balance and carrying test. On the second day of the tests and measurements, athletic skill tests were applied to the athletes. Respectively, grip strength test, 20 m running test, agility test, vertical jump test, sit-reach flexibility test, plank test and medicine ball shooting tests were applied. Measurements and tests were administered to the participants in the same order by the same researchers. A standard warm-up of 5 minutes of jogging followed by 5 minutes of dynamic stretching was performed before the athletic tests. All tests were performed at the same time of day (17:3019:30) to avoid the influence of circadian rhythms on study results. After the completion of the tests, the athletes were given the necessary time to do cool-down exercises.

\section{STATISTICAL ANALYSIS}

Statistical analyses of the data obtained in the study were made using the SPSS 18.0 program. In the analysis of the data, descriptive statistics (mean, standard deviation, median, min-max value, ratio, frequency, etc.) were used to define the characteristics of the research group and were expressed with the help of tables. In order to determine whether the research data were normally distributed, kurtosis and skewness values were examined. The values obtained according to the results of kurtosis and skewness have been found to be between -1.5 and +1.5 , and studies have shown that the data show normal distribution, and the values outside these measures do not show normal distribution [28]. Also, the homogeneity of variances was checked with Levene's test. While parametric tests were applied to the data that met all these conditions, non-parametric tests were applied to the data that did not meet the conditions. In this case, in the comparison of binary groups, independent samples $\mathrm{t}$ test from parametric tests and Mann Whitney-U test from non-parametric tests were used. Finally, Cohen's d statistics were used in the T-test analysis to calculate the strength of the relationship between the variables in the designs of the tests with significant differences. Cohen's $r$ statistics were used to calculate the strength of the relationship between the variables in the Mann Whitney-U analysis [29]. Cohen's $r$ coefficient calculated with the formula $r=Z / \sqrt{ } N$ A value of $p<0.05$ was considered statistically significant.

\section{RESULTS}

It was determined that there was a significant difference between elite and non-elite athlete groups in terms of sitting height $(\mathrm{p}<0.05)$. This difference was in favor of the elite group. The effect size of the difference between the two groups was also high $(d=1.09)$ (Table 2$)$.

As a result of the comparison of elite and Non-elite athlete groups in terms of height and body weight, a statistically significant difference was found in favor of the elite group $(p<0.05)$. The effect sizes of these differences were determined as medium-level (respectively: $r=0.39 ; 0.33$ ). There was no statistically significant difference between the groups in terms of fat percentage and BMI values ( $p>0.05$ ) (Table 3 ).

In the comparison of the speed levels of the elite and non-elite athlete groups, it was determined that there was a significant difference between the two groups $(p<0.05)$, and this difference was in favor of the elite group. In addition, the effect size of this difference between the groups was found to be high $(\mathrm{d}=0.86)$. In the comparison of the core endurance values of the groups, it was determined that there was a statistically significant difference in favor of the elite group $(p<0.05)$ and the effect size of this difference was medium $(d=0.56)$. No significant difference was found in the intergroup comparison of agility and vertical jump values $(\mathrm{p}<0.05)$ - Table 4 . 
Table 2. T-test results in terms of elite sitting height values of athletes

\begin{tabular}{|c|c|c|c|c|c|c|c|c|}
\hline \multirow{3}{*}{ Variables } & \multirow{2}{*}{\multicolumn{2}{|c|}{$\begin{array}{c}\text { Elite } \\
n=21\end{array}$}} & \multirow{2}{*}{\multicolumn{2}{|c|}{$\begin{array}{c}\text { Non-elite } \\
n=49\end{array}$}} & \multirow{3}{*}{$d f$} & \multirow{3}{*}{$\mathrm{t}$} & \multirow{3}{*}{$p$} & \multirow{3}{*}{$d$} \\
\hline & & & & & & & & \\
\hline & Mean & SD & Mean & SD & & & & \\
\hline Sitting height $(\mathrm{cm})$ & 90.19 & 4.97 & 84.97 & 4.56 & 68 & 4.260 & $0.00 *$ & 1.09 \\
\hline
\end{tabular}

$p<0.05^{*} d=$ Cohen's d effect size

Table 3. Mann-Whitney U test results in terms of elite body height, body weight, body fat percentage and BMI values of athletes

\begin{tabular}{|c|c|c|c|c|c|c|}
\hline & Mean rank & Sum of ranks & U & z & $\mathrm{p}$ & r \\
\hline \multicolumn{7}{|c|}{ Body height (cm) } \\
\hline Elite & 47.69 & 1001.50 & 258.500 & -3.283 & $0.00 *$ & -0.39 \\
\hline Non-elite & 30.28 & 1483.50 & & & & \\
\hline \multicolumn{7}{|c|}{ Body weight (kg) } \\
\hline Elite & 45.83 & 962.50 & 297.500 & -2.781 & $0.00 *$ & -0.33 \\
\hline Non-elite & 31.07 & 1522.50 & & & & \\
\hline \multicolumn{7}{|c|}{ Body fat percentage (\%) } \\
\hline Elite & 42.50 & 892.50 & 367.500 & -1.884 & 0.06 & - \\
\hline Non-elite & 32.50 & 1592.50 & & & & \\
\hline \multicolumn{7}{|c|}{ BMI $\left(\mathrm{kg} / \mathrm{m}^{2}\right)$} \\
\hline Elite & 41.29 & 867.00 & 393.00 & -1.557 & 0.11 & - \\
\hline Non-elite & 33.02 & 1618.00 & & & & \\
\hline
\end{tabular}

Table 4. T-test results in terms of elite speed, agility, vertical jump and core endurance values of athletes

\begin{tabular}{|c|c|c|c|c|c|c|c|c|}
\hline \multirow{3}{*}{ Variables } & \multirow{2}{*}{\multicolumn{2}{|c|}{$\begin{array}{c}\text { Elite } \\
n=21\end{array}$}} & \multirow{2}{*}{\multicolumn{2}{|c|}{$\begin{array}{c}\text { Non-elite } \\
n=49\end{array}$}} & \multirow{3}{*}{$d f$} & \multirow{3}{*}{$\mathrm{t}$} & \multirow{3}{*}{$p$} & \multirow{3}{*}{$d$} \\
\hline & & & & & & & & \\
\hline & Mean & SD & Mean & SD & & & & \\
\hline Speed (sn) & 3.47 & 0.34 & 3.75 & 0.31 & 68 & -3.325 & $0.00 *$ & 0.86 \\
\hline Agility (sn) & 5.85 & 0.58 & 6.08 & 0.59 & 68 & -1.479 & 0.14 & - \\
\hline Vertical jump (cm) & 33.28 & 8.81 & 31.11 & 6.39 & 68 & 1.155 & 0.25 & - \\
\hline Core endurance (sec) & 146.66 & 32.63 & 126.79 & 37.87 & 68 & 2.092 & $0.04 *$ & 0.56 \\
\hline
\end{tabular}

$p<0.05 * r=$ Cohen's $r$ effect size

A significant difference was found between the elite and non-elite groups in terms of grip strength $(\mathrm{p}<0.05)$. The effect size of this difference was determined as moderate level $(\mathrm{r}=$ -0.33). No statistically significant difference was found between the flexibility levels of the groups ( $p>0.05)$. In the comparison of the groups in terms of upper extremity strength level, a significant difference was found in favor of the elite group $(\mathrm{p}<0.05)$, and the effect size of this difference was determined at a high level $(r=0.49)$. In the comparison of the groups in terms of anaerobic power level, a significant difference was found in favor of the elite group $(\mathrm{p}<0.05)$ and the effect size of this difference was determined at a moderate level $(r=0.30)$ (Table 5).

As a result of the comparison made in terms of KTK moving sideways and walking backwards values, no statistically significant difference was found between the groups ( $p>0.05$ ) (Table 6).

As a result of the comparison made in terms of KTK jumping sideways and hopping values, a statistically significant difference $(p<0.05)$ was determined between the groups in favor of the elite group (Table 6). The effect sizes of the differences between the groups were determined as moderate ( $r=0.25 ; 0.40$, respectively) (Table 7 ). 
Table 5. Mann-Whitney U test results in terms of elite flexibility, upper extremity strength and anaerobic power values of the athletes

\begin{tabular}{|c|c|c|c|c|c|c|}
\hline & Mean rank & Sum of ranks & U & z & $\mathrm{p}$ & $r$ \\
\hline \multicolumn{7}{|c|}{ Handgrip (kg) } \\
\hline Elite & 45.93 & 964.50 & 265.500 & -2.807 & $0.00 *$ & -0.33 \\
\hline Non-elite & 31.03 & 1520.50 & & & & \\
\hline \multicolumn{7}{|c|}{ Flexibility (cm) } \\
\hline Elite & 38.19 & 802.00 & 458.000 & -0.725 & 0.46 & - \\
\hline Non-elite & 34.35 & 1683.00 & & & & \\
\hline \multicolumn{7}{|c|}{ Upper extremity strength (m) } \\
\hline Elite & 50.90 & 1069.00 & 191.000 & -4.147 & $0.00 *$ & -0.49 \\
\hline Non-elite & 28.90 & 1416.00 & & & & \\
\hline \multicolumn{7}{|c|}{ Anaerobic power (p) } \\
\hline Elite & 44.90 & 943.00 & 317.000 & -2.531 & $0.01 *$ & -0.30 \\
\hline Non-elite & 31.47 & 1542.00 & & & & \\
\hline
\end{tabular}

$p<0.05^{*} r=$ Cohen's $r$ effect size

Table 6. T-test results in terms of the elite status of the athletes' KTK moving sideways and KTK walking backwards values

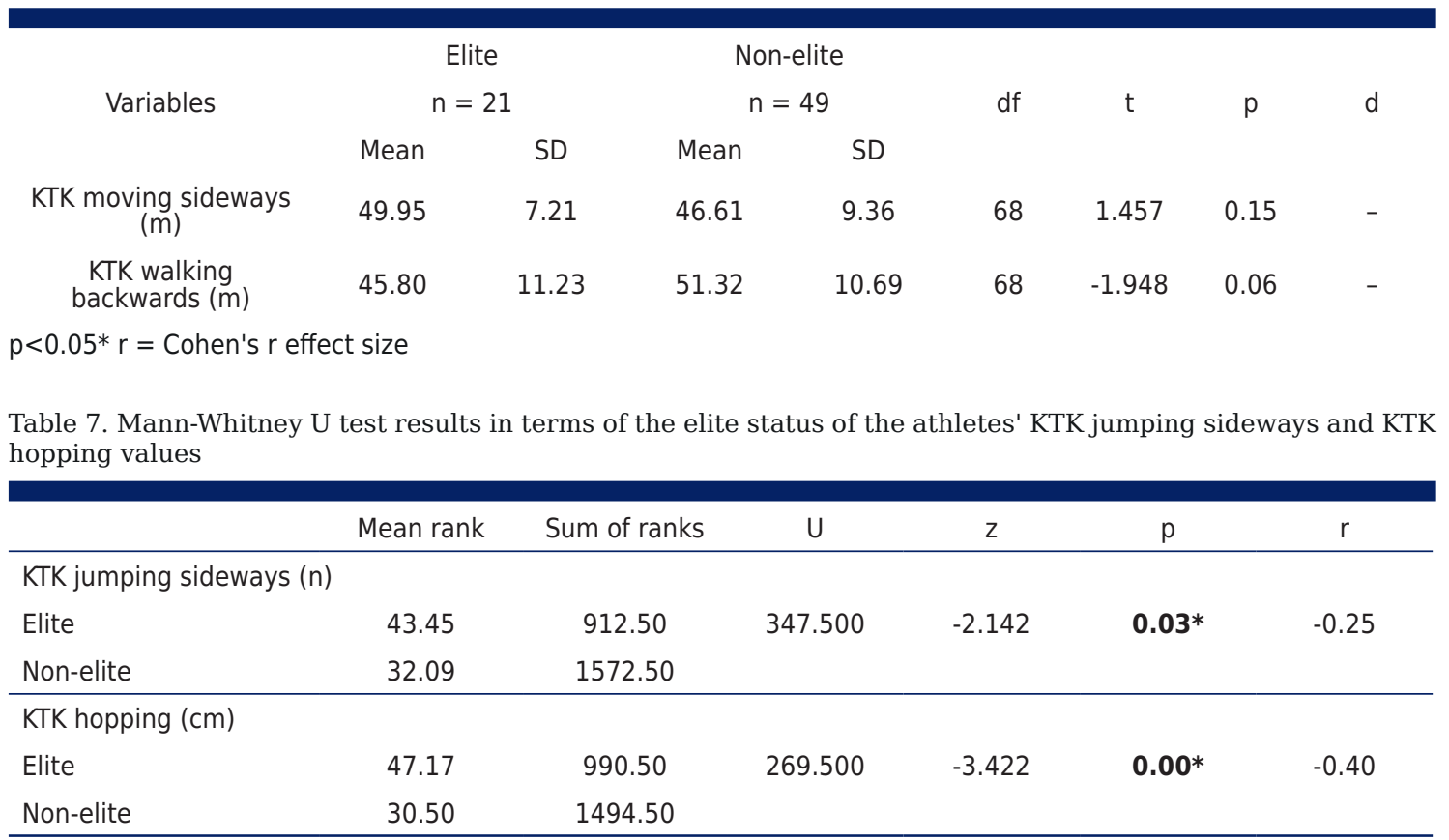

$p<0.05 * r=$ Cohen's $r$ effect size

\section{DISCUSSION}

This cross-sectional study was designed to investigate differences in anthropometry, athletic skills, and motor competencies between elite and non-elite combat athletes. While a significant difference was found in favor of the elite group in terms of height, sitting height and body weight in the research group, it was determined that there was no statistically significant difference between elite and non-elite athletes in body fat percentage and BMI values. Previous studies also showed significant differences in anthropometric characteristics between combat sport athletes in judo [3, 5], karate [3] and taekwondo [3]. While there is no significant difference in the fat percentage values of the combat athletes in the research group, it is expressed in the literature as especially in combat sports with weight categories, fat percentage is one of the most important variables [13]. There are expectations that height will be an important factor or advantage for elite taekwondo athletes [6, 12]. In a 
study conducted with taekwondo players, no significant differences were found between those groups in standing height or body stature [13]. Studies investigating the differences between the anthropometric and body compositions of elite and non-elite wrestlers have found no differences in the height, body fat percentage, lean body mass and Body Mass Index (BMI) values [30, 31, 32]. In those studies, it was stated that the difference between elite and non-elite groups was related to sports age, training history and experience. In a study evaluating the body composition of Olympic combat athletes, including judo, wrestling, taekwondo and boxing athletes, it was revealed that Olympic athletes were heavier and had higher BMI values than other competition athletes [33]. In general, the research findings are in parallel with the research results in the literature, and it is revealed that elite combat athletes are taller and heavier than non-elite ones.

In the study, when comparing the athletic skills of the groups, it was determined that there were significant differences in favor of elite combat athletes in the variables of speed, core strength endurance, grip strength, upper extremity strength and anaerobic power. There was no significant difference between the groups in agility, vertical jump and flexibility parameters. It has been determined that elite and on-elite athletes in taekwondo, which is evaluated as a combat sport, have better scores in speed and jump performances than elite taekwondo players [13]. Moreover, it was stated in this study that speed and power are indeed relevant determinants of taekwondo performance [14]. In another study, significant differences were found in favor of the elite group in anaerobic power, vertical jump, and arm strength parameters of elite and non-elite taekwondo players, while similarity was determined between the two groups in flexibility [34]. It is stated that lower extremity power generation, especially related to taekwondo, is of critical importance for the application of strong strokes [35, 36]. It has been revealed that the hand grip strength of elite and sub-elite judokas are similar [37, 38], and the elite judokas have higher values in dynamic strength values such as 1 Repetition Maximum (RM) bench press and deadlift [37]. Fagerlund and Hakkinen [13] reported differences in the maximum absolute and relative strength of the back squat between recreational and international judoka; however, no differences were detected for bench press. In addition, international medal judokas performed significantly more pull-ups, bench presses, and squats than national medal judokas. This indicates that elite judokas show more muscular endurance than sub-elite judokas [37]. In addition, agility and explosive power were found to be associated with support throwing, throwing, and clamping movements in judo $[38,40]$. In a study comparing the reactive agility and planned direction change skills of elite and sub-elite young karate players, it was determined that the reactive agility values of elite athletes were statistically shorter. There was no significant difference between planned change of direction skills [41]. In other studies, especially leg strength, core stability, and flexibility have been documented as prerequisites for kicking in both taekwondo and karate $[42,43]$. In wrestling, another sport discipline defined as a combat sport, it is stated that aerobic capacity, anaerobic power and flexibility elements have an important place in the evaluation of athletes in the elite performance athlete group [44]. In addition, Roemmich and Frappier [45] revealed that the grip strength of the left hand, flexibility of the lower extremities and hamstrings, push-ups, right quadriceps strength, and the total distance covered in a 12-minute run are important in predicting wrestling success.

In the comparison of the motor competence elements of the research groups, significant differences were found in favor of the elite group in the side jump and jumping characteristics, while no difference was found between the groups in the backward walking and carrying characteristics. In contrast to the sport-specific motor skill tests, the KTK test used in the study is affected only to a limited extent by sport-specific training, making it easier to distinguish innate ability from test scores that result from training [13]. General motor coordination has proven to be a valuable indicator of an athlete's potential to progress and, therefore, an important skill trait in skill-based sports, such as artistic gymnastics [46] 
and combat sports [3, 5, 13]. For example, elite judo athletes demonstrated better motor coordination and balance compared to their non-elite peers [47]. However, it is stated that an athlete with better coordination can learn new techniques faster and easier [46]. In the KTK test applied to young taekwondo players, a different result was obtained from the results of our study. In this study, it was determined that the elements of carrying and walking back were distinguishable between groups according to their elite performance abilities [13]. Moreover, Krstulovic et al. report that motor coordination and balance are better developed in elite judo and taekwondo athletes compared to non-elite [40]. Motor coordination measures seem to be much more important when determining future performance potential, especially for identifying and exploring potential in young athletes $[3,48,49]$. In the literature, the number of studies examining the motor coordination feature in karate and wrestling disciplines is very few. When the motor coordination of karate and non-athletes were compared, it was determined that karate athletes had very high scores [50]. In a study comparing the motor coordination of medalist and non-medalist fencers, it was determined that the scores between the groups were quite close [48].

Taken together, the combination of athletic skills, anthropometric structure and motor coordination can help coaches and performance professionals better understand their athletes' performance and discover the best approach to improve their training organization. In addition, considering the significant differences between elites and non-elites in this study, more attention should be paid to sprinting, anaerobic power, upper extremity and core strength training. However, these variables can also be used in combat sports as an early form of detection for young talented athletes. Judo, karate, taekwondo and wrestling are defined as combat sports in the study. Although these sports disciplines show similarities with each other in athletic and technical elements, they can show differences in some physiological and morphological features. Therefore, this can be considered as one of the limitations of the study. In addition, the small number of samples and the evaluation of male and female groups together can be another limitation of the study.

\section{CONCLUSIONS}

This research was successful in determining how elite and non-elite combat athletes differ in terms of anthropometric characteristics, athletic skills and motor competence. Especially, in terms of height and body weight, speed, anaerobic power, grip, upper extremity and core strength, as well as motor proficiency related to anaerobic power, there seem to be important distinctions between athletes who reach the national peak and those who do not. Combat sports coaches and federations can use this information in talent identification and development programs, but it should be noted that anthropometry, athletic skill and coordination are only a part of talent. In the in-depth evaluation of the athlete, psychological and cognitive factors related to the sports discipline and other social-affective characteristics must be taken into account. All these variables are also valuable for assessing the athlete's progress and the effectiveness of a training program.

\section{REFERENCES}

[1] Birrer RB. Trauma epidemiology in the martial arts: the results of an eighteen-year international survey. Am J Sport Med. 1996;24(6_suppl):72-9. https://doi.org/10.1177/036354659602406S21

[2] Williams AM, Reilly T. Talent identification and development in soccer. J Sport Sci. 2000;18(9):657-667. https://doi. org/10.1080/02640410050120041

[3] Pion J, Fransen J, Lenoir M, Segers, V. The value of non-sport-specific characteristics for talent orientation in young male judo, karate and taekwondo athletes. Arch Budo. 2014;10(1):147-154.

[4] Pallare's JG, Lo'pez-Gullo'n JM, Torres-Bonete MD, Izquierdo M. Physical fitness factors to predict female Olympic wrestling performance and sex differences. J Strength Cond Resh. 2012;26(3):794-803. https://doi.org/10.1519/JSC.0b013e31824741e7

[5] Norjali R, Torfs M, Mostaert M, Pion J, Lenoir M. Predicting judo champions and medallists using statistical modelling. Arch Budo. 2017;13:161-7. 
[6] Kazemi M, Waalen J, Morgan C, White AR. A profile of Olympic taekwondo competitors. J Sport Sci Med. 2006;5(CSSI): 114-121.

[7] Franchini E, Nunes AV, Moraes JM, Del Vecchio FB. Physical fitness and anthropometrical profile of the Brazilian male judo team. J Physiol Anthropol. 2007;26(2):59-67. https://doi.org/10.2114/jpa2.26.59

[8] Junior ACT, Junior JAO, Gonçalves B, Drigo AJ, Dos-Santos JW. Body composition, strength and specific physical fitness as factors to discriminate performance in judokas. Arch Budo. 2018;14:117-123.

[9] Silva IO, Santos JDM. Relação entre percentual de gordura corporal e desempenho em atletas de judô no campeonato brasileiro sênior 2004 [Relationship between body fat percentage and performance in judo athletes in the 2004 senior Brazilian championship]. Confederação Bras Judô. 2005;1-19.

[10] Ghrairi M, Hammouda O, Malliaropoulos N. Muscular strength profile in Tunisian male national. Muscles Ligaments Tendons J. 2014;4(2):149-153. https://doi.org/10.32098/mltj.02.2014.10

[11] Torres-Luque G, Hernández-García R, Escobar-Molina R, Garatachea N, Nikolaidis PT. (2016). Physical and physiological characteristics of judo athletes: An update. Sports. 2016;4(1):20. https://doi.org/10.3390/sports4010020

[12] Poliszczuk T, Omiecińska I, Mańkowska M, Jankowska E, Poliszczuk D. Somatic profile of elite polish female taekwon-do (itf) athletes and their relationships to performance. In: Niźnikowski T, Sadowski J, Starosta W, eds. Coordination Abilities in Physical Education, Sports and Rehabilitation. Warsaw: Józef Piłsudski University of Physical Education in Warsaw; 2016, 202-217.

[13] Norjali Wazir MRW, Van Hiel M, Mostaert M, Deconinck FJ, Pion J, Lenoir M. Identification of elite performance characteristics in a small sample of taekwondo athletes. PloS ONE. 2019;14(5):1-12. https://doi.org/10.1371/journal. pone.021735e0217358.

[14] Pieter W, Bercades LT. Strength correlates of kicking force in young taekwondo-in. The 2nd international symposium for taekwondo studies. Seoul, South Korea; 2009.

[15] Doğan E. Historical development of karate sport in the Republic of Turkey (1970-2000). Master Thesis. Marmara University, 2003.

[16] Gabbett T, Benton D. Reactive agility of rugby league players. J Sci Med Sport. 2009;12(1):212-214. https://doi.org/10.1016/j. jsams.2007.08.011

[17] Serpell BG, Ford M, Young WB. The development of a new test of agility for rugby league. J Strength Cond Res. 2012;24(12):3270-3277. https://doi.org/10.1519/JSC.0b013e3181b60430

[18] Pekel HA et al. Evaluation of some anthropometric physical and physiological characteristics of Greco-Roman and freestyle youth national team wrestlers. The 9th international sports sciences congress. 3th-5th November 2006, Muğla, Turkey; 2006.

[19] Özer Ö, Kılınç F. Elite athletes in individual and team strength, speed and flexibility to compare their performance. J Human Sci. 2012;9(1):360-371.

[20] Roemmich JN, Frappger JP. Physiological determinants of wrestling success in high school athletes. Pediatr Exerc Sci. 1993;5:134-144. https://doi.org/10.1123/pes.5.2.134

[21] Harriss DJ, Atkinson G. Ethical standards in sport and exercise science research: 2016 update. Int J Sports Med. 2015;36(14):1121-4. https://doi.org/10.1055/s-0035-1565186

[22] Matthys SP, Vaeyens R, Vandendriessche J, Vandorpe B, Pion J, Coutts AJ, et al. A multidisciplinary identification model for youth handball. Eur J Sport Sci. 2011;11(5):355-63. https://doi.org/10.1080/17461391.2010.523850

[23] Karacabey K. Performance and agility tests in sports. Int J Hum Sci. 2013;10(1):1693-1704.

[24] Reiman MP, Manske RC. Functional testing in human performance. Champaign, Illinois: Human Kinetics; 2009. https:// doi.org/10.5040/9781492596882

[25] Kamar A. (2008). Ability, skill and performance tests in sports. Ankara: Nobel Publications; 2008.

[26] Wood R. Modified Sit and Reach Test. Topend Sports Website, 2008. https://www.topendsports.com/testing/tests/sit-andreach-modified.htm, Accessed 08.08.2021

[27] Kiphard EJ, Schilling F. Körperkoordinationstest für kinder, Beltz TestGmbH, Weinheim; 2007.

[28] Tabachnick BG, Fidell LS. Using Multivariate Statistics. Boston: Allyn and Bacon; 2013.

[29] Büyüköztürk Ş, Çakmak EK, Akgün ÖE, Karadeniz Ş, Demirel F. Scientific research methods. Ankara: Pegem Academy; 2016.

[30] Pallares JG, Lopez JM, Muriel GX, Mikel Izquierdo AD. Physical fitness factors to predict male Olympic wrestling performance, Eur J Appl Physiol. 2001;111:1747-1758. https://doi.org/10.1007/s00421-010-1809-8

[31] Karninčić H, Tocilj Z, Uljević O, Erceg M. Lactate profile during Greco-Roman wrestling match.J Sport Sci Med. 2009;8(CSSI 3):17-19.

[32] Demirkan E, Kutlu M, Koz M, Ünver R, Bulut E. The investigation of body composition and hydration changes in elite wrestlers. Selcuk University J Phys Educ Sport Sci. 2012;14(2):179-183.

[33] Reale R, M. Burke LM, Cox GR, Slater G. Body composition of elite Olympic combat sport athletes. Eur J Sport Sci. 2020;20(2):147-156. https://doi.org/10.1080/17461391.2019.1616826

[34] Ghorbanzadehkoshki B. The analysis of some physical characteristics of national or non-national taekwondo athletes. Master Thesis, Ankara University, 2009.

[35] Ball N, Nolan E, Wheeler K. Anthropometrical, physiological, and tracked power profiles of elite taekwondo athletes 9 weeks before the Olympic competition phase. J Strength Cond Res. 2011;25(10):2752-63. https://doi.org/10.1519/ JSC.0b013e31820d9f3f

[36] Chiodo S, Tessitore A, Cortis C, et al. Stress-related hormonal and psychological changes to official youth Taekwondo competitions. Scand JMed Sci Sports. 2011;21(1):111-9. https://doi.org/10.1111/j.1600-0838.2009.01046.x

[37] Drid P, Casals C, Mekic A, Radjo I, Stojanovic M, Ostojic SM. Fitness and anthropometric profiles of international vs. national judo medalists in half-heavyweight category. J Strength Cond Res. 2015;29(8):2115-2121. https://doi.org/10.1519/ JSC.0000000000000861

[38] Franchini, E, Takito, MY, Kiss, MAPD, and Strerkowicz, S. Physical fitness and anthropometrical differences between elite and non-elite judo players. Biol Sport. 2005;22:315-328.

[39] Fagerlund, R and Ha"kkinen, H. Strength profile of Finnish judoists measurement and evaluation. Biol Sport. 1991;8:143-149. 
[40] Krstulović S, Zuvela F, Katić R. Biomotor systems in elite junior judoists. Coll Antropol. 2006;30(4): 845-851.

[41] Ylldız M, Cigirdik R. Comparison of the reactive agility and preplanned change of direction abilities of the elite and sub elite young karate players. CBU J Phys Edu Sport Sci. 2018;13(2):192-199.

[42] Cesari P, Bertucco M. Coupling between punch efficacy and body stability for elite karate.J Sci Med Sport. 2008;11(3):353356. https://doi.org/10.1016/j.jsams.2007.05.007

[43] Sadowski J, Gierczuk D, Miller J, et al. Success factors in elite WTF taekwondo competitors. Arch Budo. 2012;8(3):141-146. https://doi.org/10.12659/AOB.883279

[44] Demirkan E, Koz M., Kutlu M, Favre M. (2015). Comparison of physical and physiological profiles in elite and amateur young wrestlers. J Strength Cond Res. 2015;29(7):1876-1883. https://doi.org/10.1519/JSC.0000000000000833

[45] Roemmich JN, Frappier JP. Physiological determinants of wrestling Success in high school athletes. Pediatr Exerc Sci. 1993;5:134-144. https://doi.org/10.1123/pes.5.2.134

[46] Vandorpe B, Vandendriessche JB, Vaeyens R, et al. The value of a non-sport-specific motor test battery in predicting performance in young female gymnasts. J Sport Sci. 2012;30(5):497-505. https://doi.org/10.1080/02640414.2012.654399

[47] Krstulović S, Z` uvela F, Katić R. Biomotor systems in elite junior judoists. Coll Antropol. 2006;30(4):845-51.

[48] Norjali Wazir MR, Mostaert M, Pion J, Lenoir M. Anthropometry, physical performance, and motor coordination of medallist and non-medallist young fencers. Arch Budo. 2018; 14:33-40.

[49] Pion JA, Fransen J, Deprez DN, Segers VI, Vaeyens R, Philippaerts RM, et al. Stature and jumping height are required in female volleyball, but motor coordination is a key factor for future elite success. J Strength Cond Res. 2015;29(6):1480-5. https://doi.org/10.1519/JSC.0000000000000778

[50] Simonović Z, Bubanj S, Projović A, Kozomara G, Bubanj R. Differences in motor abilities between karate athletes and nonathletes. Sport SPA. 2011;8(1):15-19. 